\title{
Pro and con features regarding underground gas storage in depleted reservoirs versus saline deposits
}

\author{
Ionuț Lungu ${ }^{1, *}$, Florinel Dinu ${ }^{1}$, Maria Stoicescu ${ }^{1}$, Silviu Suditu ${ }^{1}$ and Ioana-Cornelia Mitrea \\ (Rosu) ${ }^{1}$ \\ ${ }^{1}$ Petroleum-Gas University of Ploiesti, Bd. Bucuresti no.39, 100680, Ploiesti
}

\begin{abstract}
Underground storage of natural gas represents an efficient solution to cover fluctuations in natural gas consumption during the cold season and/or special situations like emergencies. The paper aims to presents the natural gas underground storages technologies in saline deposits and depleted reservoirs, as well as the pros and cons features of using of those methods..
\end{abstract}

\section{Introduction}

The natural gas exploitation industry has developed remarkably in recent years due to the increase in natural gas consumption. Thus, due to the variation of natural gas consumption during the year (in the hot season the demand is lower and in the cold season the demand is higher), the underground storage of natural gas becomes a necessary technology for the natural gas exploitation industry.

Underground storage of compressed natural gas in oil and gas fields has been used as a common efficient technology since 1915, in order to regulate the supply of gas to meet the demand.

Underground gas storage of natural gas is an efficient process that ensures the constant supply of natural gas, through transmission pipelines, depending on the variable demands of the market, which depend on weather or economic considerations.

Underground natural gas storage depots also have a strategic role to play in ensuring the supply of natural gas in case of emergency (calamities, reduction of import quantity, etc.).

\section{Underground gas storage in saline deposits (UGSSD)}

Generally, the cavern built in saline deposits for the natural gas storage has the following characteristics:

- Depth between 300 - $2000 \mathrm{~m}$;

- Thickness from 10 to 100 meters (if the thickness of the salt layer is less than $10 \mathrm{~m}$ it is very difficult to make the cave through the dissolution process and the gas volum can be stored is very small and does not cover the investment);

\footnotetext{
* Corresponding author: rufay 18@yahoo.com
} 
- Volume varies from 30 to 500 million $\mathrm{m}^{3}$;

- Pressure gradient at the casing shoe : $1.5-2.5 \mathrm{bar} / 10 \mathrm{~m}$;

- Pressure gradient at cavern medium depth : 2 bar/10 m;

- Pressure: 25 - 225 bar. [1,3]

\subsection{Building the salt cavern}

In order to build such a cavern (Fig 1,2) a well has to be drilled; casing 1 is cemented and after that casings 2 and 3 are inserted and the diameter is decreased successively. Those two casings are free and their length can easily be changed from the surface to obtain the desired shape of the cavern

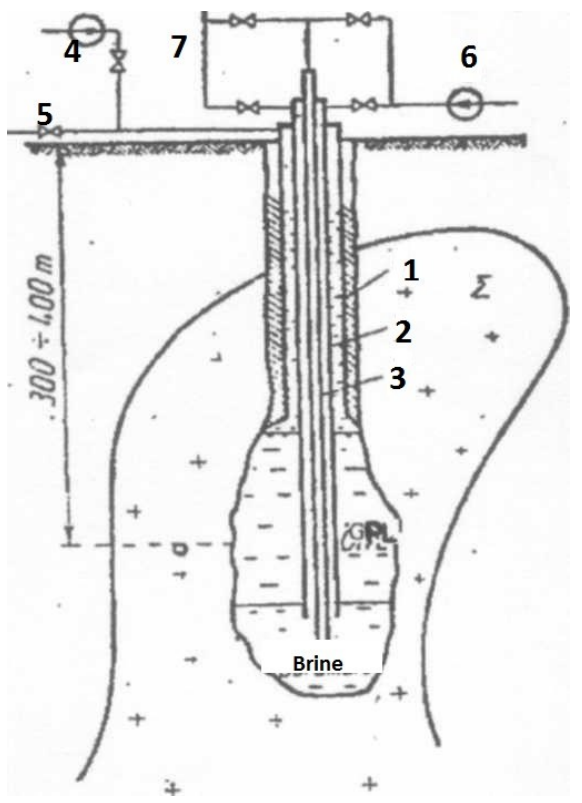

Fig. 1. Natural gas storage in saline cavern [2]

Using pomp 6, freshwater is pumped into the salt layer through casing 3, and after the saline water formed is evacuated to the surface using the annulus space between strings 2 and 3, and then through pipeline 7 . To obtain certain shapes of the cavern, the freshwater and brine can be reversed.

Using a "Sonar" device the shape of the cavern can be controlled.

The natural gas is introduced using pomp 4; the gas replaces the brine which is brought to the surface through string 3 and pipeline 7

At the base of the cavern is always maintained a layer of brine, in which strings 2 and 3 are entering, to avoid natural gas losses.

The separation between the natural gas that is injected into the cavern and the brine is made by gravitational segregation.

The stability of the cavern is not an issue, because the pressure is maintained at high values. At the end of the process, the cavity tightness is checked.

The separation between the two fluids is done by gravitational segregation.

It is mandatory to have brine reserves, not to affect the cavern volume. Brine manipulation creates numerous issues (i. e., salt precipitation, salt dilution into the well, etc.). Freshwater can also be used in the production process, but additional measures have to be considered to follow 
the process (i. e., echometry to determine the shape and dimensions of the cavern). This solution constitutes a prerequisite for progressively increasing the size of the cavern. [1]

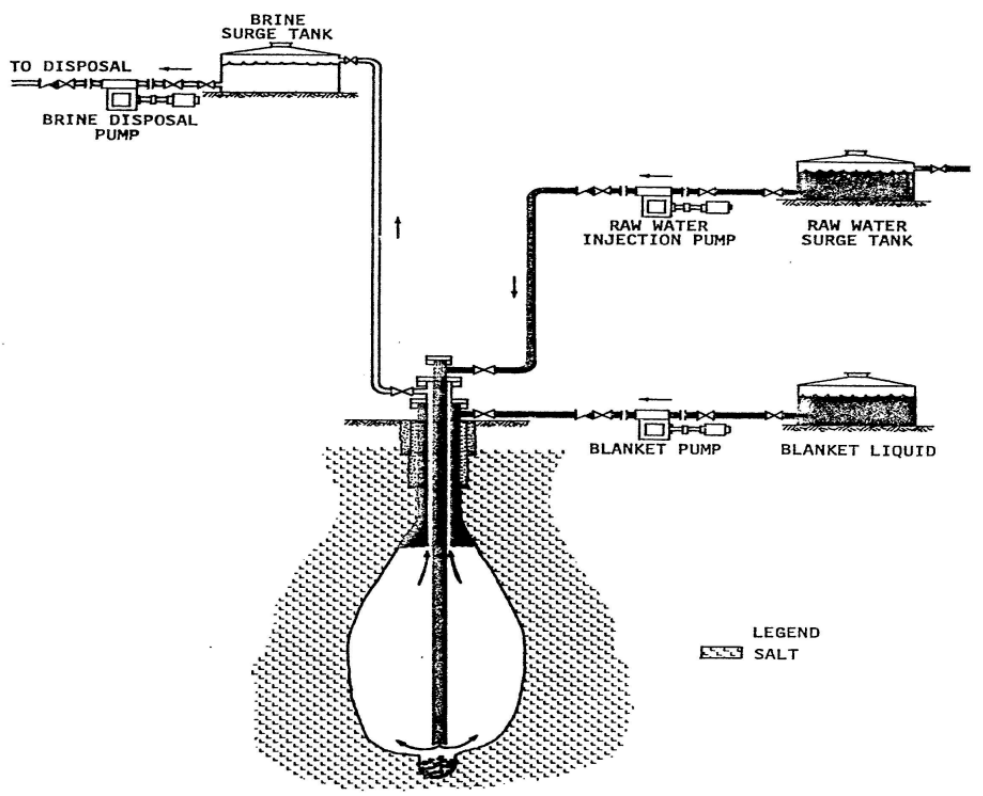

Fig. 2. Salt cavern building using direct circulation [5]

\subsection{Operating procedures}

Operation of gas-filled salt caverns is normally done by the sliding pressure method (by compression and decompression between a minimum and maximum pressure). This method allows the division of the amount of gas into working gas, which is the amount of gas extracted from the cavern during normal operation and the gas cushion that must remain in the cavern to ensure its stability[4]

The amount of gas cushion needed to ensure the stability of the cave varies depending on the geology of the structure, depth, etc., and represents approximately one-third of the amount of gas stored.

Cavern operating procedures are generally limited by both the maximum rate of change and pressure in the unit of time and the maximum rate of flow rate variation within the drill string. Besides, recovery times of higher storage pressure are required after periods of very low pressures [5].

Because that during the use of caverns, brine always remains at the bottom of the cavern (cavern basin) the water will evaporate and this leads to increased gas humidity. Due to the increase in gas humidity, it is necessary to dry them.

\subsection{Costs of UGSSD method}

In order to determine the cost for underground storage in salt caverns the following elements are needed:

- Salt doom location using seismic and gravimeter

- Number of wells that will be used

- Specific installation for cleaning the cavern 
From technical and economic reasons, the injection process is 20 days and the extraction process is 10 days. The investment value in a salt cavern is far superior to the ones in depleted reservoirs, but on the other hand, the storage cost is below. According to the researches, the investment cost in a salt cavern is double compared to the one in depleted reservoirs. At 6 cycles per year, the highest cost in a salt cavern is lower than the one in depleted reservoirs. [6]

\subsection{Advantages of UGSSD method}

The advantages of underground gas storage in saline deposits are as follows:

- high rates can be obtained, compared to the stored quantity

- the big areal extent of the salt layers over the globe

- the extraction duration is of the week's orders; several cycles can be achieved per year

- when multiple cycles are done per year, the operating costs are smaller than in the depleted reservoirs or aquifer reservoirs. [7]

\subsection{Disadvantages of UGSSD method}

The disadvantages of underground gas storage in saline deposits are as follows:

- Investment value is far superior to the one in depleted reservoirs

- The brine removal resulted in the excavation process create serious problems

- The cavern volume can decrease due to the salt creep phenomenon

\section{Underground gas storage in depleted reservoirs (UGSDR)}

The most common method used for underground gas storage is in depleted reservoirs. The first step for this project is the conversion of production reservoirs into storage reservoirs.

A depleted reservoir must fulfill the flowing conditions to become reservoir storage:

- To be sealed by impermeable rocks or sealed faults; which will prevent leaks of the gas in the neighboring formation.

- High effective porosity and permeability

- Not to be in communication with active aquifer

- High volume (Fig 3)

When a depleted gas reservoir is considered to be converted into underground storage, the volume which will be circulated (through injection/extraction) must represent 60 up to $75 \%$ of the initial gas in place of the field, the rest representing the amount of cushion gas. This amount of stored gas should be recovered in $\sim 120$ days, which represents the maximum recovery time for a storage cycle. This process assumes more production wells than the ones utilized in the production period and an adequate collecting process. The system used for the collecting process is made of surface facilities (compressors, pipelines for gas transportation, the equipment used for the injection/extraction wells). The system must have high flexibility which will ensure the gas consumption fluctuation during the winter due to the temperature variations. [7] 


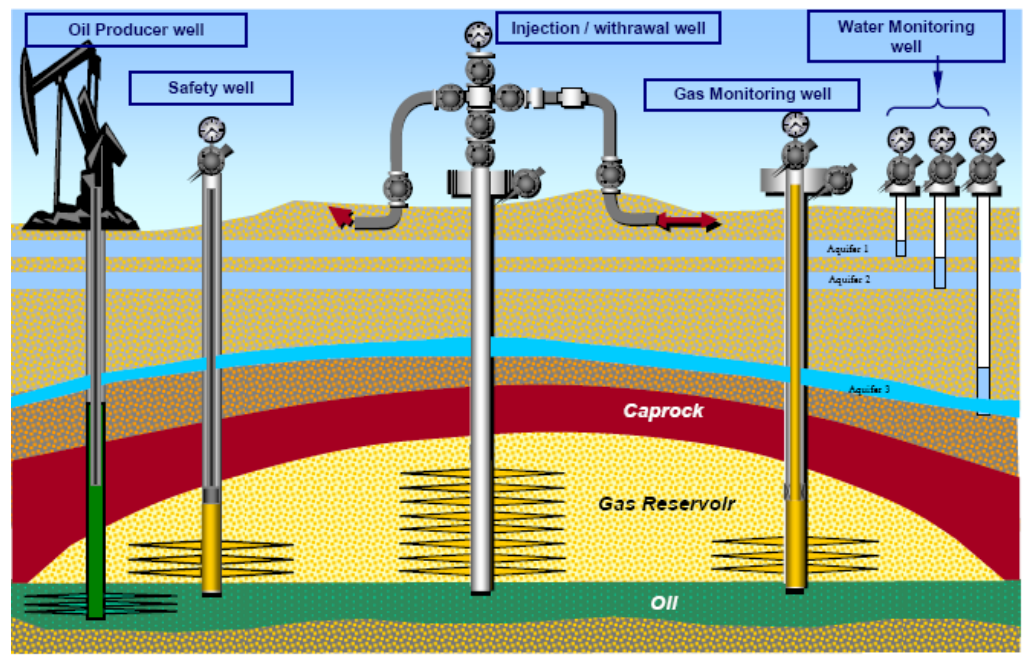

Fig. 3. Schematic diagram showing a typical setup of a hydrocarbon reservoir [8]

\subsection{Converting depleted gas reservoirs into underground gas storage deposits}

Depleted gas reservoirs or partly depleted gas reservoirs are suitable options for underground gas storage. To switch from a depleted reservoir into an underground gas storage deposit the following steps must be followed [7]:

- Gathering of geological information as well as reservoir engineering data, from the beginning of the production period, which will include: the area of the reservoir, the thickness, permeability, porosity, initial pressure, reservoir temperature, gas composition and gas production related to reservoir pressure.

- Existing wells inventory and evaluation of mechanical well integrity as well as the workover operations made during the production time

- Volume calculation of the area which can be used for the deposit.

- Defining the number of wells that will be needed for the injection and extraction process.

- Establish the needed compressibility capacity, defining the collecting network and the conditions which the stored gas must fulfill.

Also, some information regarding the field are needed:

- Geological information

- Initial reservoir pressure

- Gas production related to reservoir pressure

- Reservoir temperature

- Gas composition; the specific weight of the gas

- Number of drilled wells, their locations; depths and data of existing cores

- Well log information

- Reservoir structure (i. e., structural and thickness maps)

- Flow rates (layer-well influx; rates per well in different circumstances)

- Surface Facility plan (i. e., compressors, flow lines, gas production installation)

- Mechanical characteristic of the wells[8]

In order to determine the maximum quantity stored into a reservoir, the maximum pressure is established, as well as the minimum pressure. The maximum pressure of the reservoir is 
computed based on reservoir engineering data, in correlation with theconditions of the tightness of the wells.

For the old wells, an integrity check is done for the cement ring, using ultrasounds to check its tightness and adhesion. If by measuring the wall thickness an advanced usage is determined; a cemented liner will be placed, or one liner with packer and no-corrosive fluid in the annulus space.[8]

The graph between the reservoir pressure $\mathrm{p}$ and the compressibility factor $\mathrm{z}$, depending on the amount of extracted gas allows the computation of initial gas in place and the determination of the gas quantity that can be stored at a certain pressure; if there is and nonpermeable boundary layer.(fig. 4).

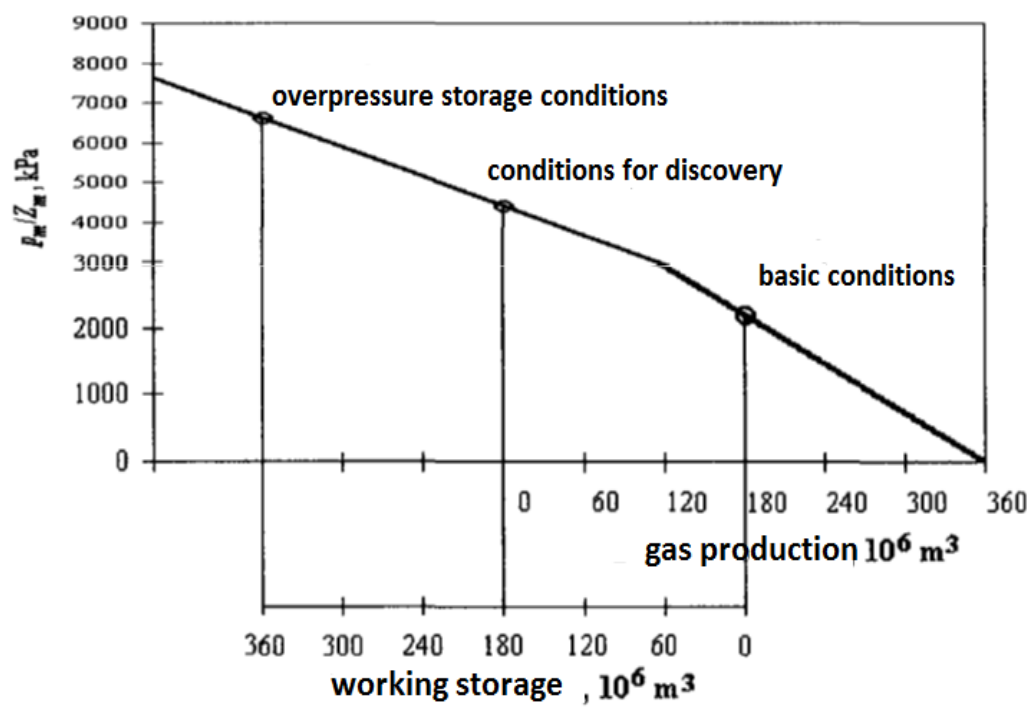

Fig. 4. Graph presenting report (p/z) depending on the extracted amount of gas [2]

\subsection{Costs of UGSDR method}

Because of the known properties of the reservoirs and the existence of porous permeable layers, of the existing drilled wells and surface facilities; the investment cost is reduced, there for the project is easier compared to other methods of gas storage.

For additional benefits; reinjecting the gas is associated with reservoir pressure increase, which can also lead to a higher rate of oil recovery

\subsection{Advantages of UGSDR method}

The advantages of underground storage of natural gas in depleted reservoirs are as follows:

- High flow rates can be daily obtained when a reservoir with high porosity and permeability is used

- The investment cost is lower compared to others because the reservoir characteristics are known, and most of the facilities are already in place(wells, pipelines)

- Low operating costs

- The process can lead to an increase in oil recovery factor; in case a depleted oil reservoir with gas cap is used.[9] 


\subsection{Disadvantages of UGSDR method}

The disadvantages of underground storage of natural gas in depleted reservoirs are as follows:

- Requires the use of inactive stocks that represent an important asset

- Possible gas losses

- Building a storage can take several years

\section{Conclusions}

1. Underground gas storage in depleted oil and gas reservoirs involves gas injection in the period with low market demand, followed by gas extraction in the time when the demand exceeds the daily production.

2. The reservoir used for gas storage can provide gas stocks for unforeseen accidents of the normal supply.

3. The costs required for the process of underground storage of natural gas in depleted deposits can be reduced (when the structure of the deposit allows this) by using existing drilling on the surface of that field, for the cycles of injection and extraction of natural gas.

4. To follow the injection/extraction process, monitoring wells are used to follow reservoir parameters (pressure/temperature) during the production period of the gas reservoir deposit

5. The cost of building the cave and its stability are influenced by the presence of impurities and intercalations of clay rocks in the salt layers.

6. When the pressure reaches the minimum value, a certain amount of gas representing $50 \%$ of storage capacity remains in the reservoir and it is known as gas buffer in underground gas storage in depleted reservoirs.

7. From technical and economic reasons, the injection process is 20 days and the extraction process is 10 days of underground ground gas storage in salt deposits.

8. The investment value for saline deposit it is far superior to the one needed for depleted reservoir storage, but the put-away costs are lower.

9. The underground storage of natural gas in depleted deposits is a complex process based on geological studies which determines the geological model of the field targeted for underground gas storage, numerical simulation of the equations of state of the studied field in order to determine the necessary storage conditions. and for the underground storage of natural gas in saline deposits, in addition to geological studies and numerical simulations, geotechnical studies are also performed to determine the mineralogical composition of the salt intercalations, to determine parametrically the geomechanics of the salt.

10. Monitoring gas storage in a depleted reservoir involves the data analysis of the data which detects the first undesired gas movements. The system taken into account must include, besides the reservoir itself the following elements: surface pipelines; wells; sealing layers below and above reservoir layer; as well as the neighboring zones over a 1.5 up to $5 \mathrm{~km}$ distance.

11. The operating pressures are observed daily; as an insurance method from the piezometric wells.

\section{References}


1. D.J. Evans, An appraisal of Underground Gas Storage technologies and incidents, for the development of risk assessment methodology (British Geological Survey, Nottingham, 2007)

2. Al. Soare., M. Zamfirescu, Inmagazinarea gazelor naturale, (Editura Universităţii PetrolGaze din Ploieşti, 2005).

3. I. Lungu, D. Frunzescu, F. Dinu, G. Branoiu, C. Jugastreanu, Geolinks International Conference on Geosciences 2019, Is there a future for oil and gas exploration in Romania? (Athens, Greece, 2019)

4. F. Dinu, Extracţia si prelucrarea gazelor naturale, (Editura Universităţii Petrol-Gaze din Ploieşti, 2013).

5. A.H. Medley, Regional Gas Industry Symposium of the Society of Petroleum Engineers, Storage of Natural Gas In Salt Caverns (Omaha, Nebraska, 1975).

6. X.L. Shi, C.H. Yang, Y.P. Li, J.L. Li, H.L. Ma., T.T Wang, Y.T. Guo, $51^{\text {st }}$ US Rock Mechanics / Geomechanics Symposium, Development prospect of salt cavern gas storage and new research progress of salt cavern leaching in China (San Francisco, 2017).

7. J.M. Campbell,Gas Conditioning and Processing, I: The Basic Principles, (Campbell Petroleum Series, 1993)

8. C.I.C. Anyadiegwu, Asia Pacific Journal of Multidisciplinary Research (2014)

9. N. Alleman, GWPC 2016 UIC Conference, Underground Natural Gas Storage in the U.S. State of Play (Denver, 2016) 